\title{
Medical management of cervical pregnancy following in vitro fertilization
}

\author{
Nilofar I. Yelurkar*, Meena N. Satia, Vijaya R. Badhwar
}

Department of Obstetrics and Gynaecology, D. Y. Patil Medical College, Nerul, Navi Mumbai, Maharashtra, India

Received: 21 March 2021

Revised: 16 April 2021

Accepted: 17 April 2021

\section{*Correspondence:}

Dr. Nilofar I Yelurkar,

E-mail: ntdanwade@gmail.com

Copyright: (C) the author(s), publisher and licensee Medip Academy. This is an open-access article distributed under the terms of the Creative Commons Attribution Non-Commercial License, which permits unrestricted non-commercial use, distribution, and reproduction in any medium, provided the original work is properly cited.

\begin{abstract}
Cervical ectopic gestation is a serious and potentially lethal condition encountered in patients undergoing invitro fertilization. Familiarity with these complications will allow accurate and timely diagnosis and help avert potentially disastrous consequences We report a rare case of cervical pregnancy after in vitro fertilization and embryo transfer successfully treated with Methotrexate.
\end{abstract}

Keywords: Cervical ectopic, Methotrexate, Medical management, Cervical pregnancy, Beta hcg

\section{INTRODUCTION}

Assisted reproductive technologies are associated with many obstetric complication. The past decade has seen increase in the incidence of assisted conception. ${ }^{1}$ At least $12 \%$ of women have sought infertility treatment at some point, and assisted reproductive technology is involved in over $1 \%$ of births each year. ${ }^{2}$ There is also an increased risk of complications like ectopic pregnancy following ART with a relative increased risk for rarer and more lethal forms including interstitial and cervical ectopic pregnancy. Cervical pregnancy is a rare and potentially lethal form of gestation with incidence ranging from 1:2500 to $1: 12000$ clinical pregnancies. ${ }^{1}$ Patients with suspected ectopic pregnancy are initially evaluated with quantitative measurement of serum $\beta$-hCG and also 3D TVS. In general, transvaginal US should demonstrate at least a gestational sac when serum $\beta$-hCG levels exceed $2000 \mathrm{mIU} / \mathrm{mL}$ (3rd International Standard). ${ }^{3}$ If no gestation sac is seen despite beta Hcg being elevated one should think of other radiological modalities for the diagnosis of ectopic pregnancy However, it is important to note that up to $35 \%$ of ectopic pregnancies may not display any extrauterine mass. ${ }^{4}$ Close clinical surveillance in conjunction with serial measurements of serum $\beta$-hCG is crucial in these cases. If the beta Hcg levels do not double every 48 hours one has to think about ectopic pregnancy and evaluate accordingly If the serum $\beta$-hCG level is below the threshold and no abnormalities are seen the patient is usually followed up with serial measurements of serum $\beta$-hCG or Sonography until an intrauterine or ectopic pregnancy is demonstrated as was seen in our patient Careful evaluation of the adnexa is critical in this patient population even when an intrauterine pregnancy has been confirmed Ultrasonography is the first-line imaging modality for the evaluation of complications of ART.

\section{CASE REPORT}

43 year old patient with secondary infertility, conceived with Donor embryo transfer presented to her gynaecologist with complaints of bleeding per vaginm 15 days after positive beta hCG report On general examination her vital parametres were stable and pelvic examination revealed a bulky soft uterus with ballooned cervix with os closed and blood stained discharge per vaginum and hence a clinical impression of threatened was made and a sonography was advised Ultrasound was suggestive of cervical pregnancy in view of normal sized uterus with ET of $7 \mathrm{~mm}$ with well-defined gestational sac implanted in the cervical canal with good trophoblastic 
reaction. Yolk sac present and fetal pole with CRL 20 $\mathrm{mm}$ corresponding to 5 weeks of pregnancy Fetal cardiac activity was present. On colour doppler minimum flow seen in trophoblastic rim. Both ovaries and adenexa were normal. The patient was referred to our institute for further management of cervical pregnancy. Patient was married for 14 years. She had a missed abortion of 8 weeks gestation 6 years back when she had taken ovulation induction agents. She had undergone D and C for the same. Diagnostic laparoscopy was done in 2013 in which, uterus was normal, left fallopian tube was blocked and Rt tube delayed spill was present.

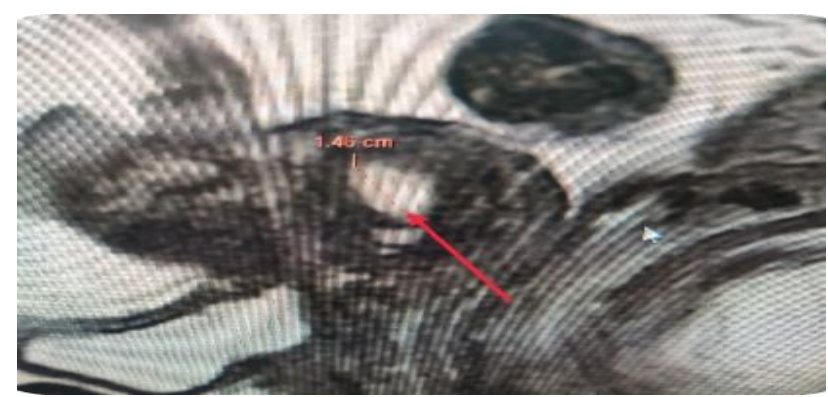

Figure 1: Gestational sac $1.5 \times 2 \mathrm{~cm}$ in endocervical canal.

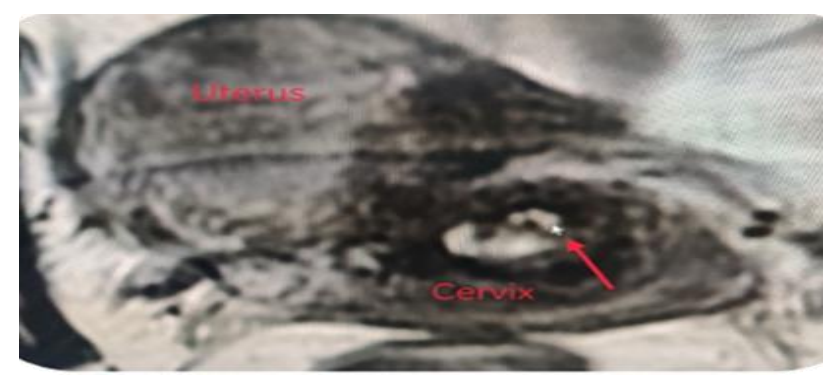

Figure 2: Fetal pole in gestational sac.

Patient was a known case of chronic hypertension on tablet labetalol $100 \mathrm{mg} \mathrm{BD}$ and tablet Nifedepin $5 \mathrm{mg}$ OD. She was hypothyroid on tablet Eltroxin $12.5 \mathrm{mcg}$ per day. Prior to Donor embryo transfer Office Hyseroscopy was done in which both ostias were not seen and Endocervical canal was normal. ${ }^{2}$ blastocysts were transferred on 19/12/2019. Post embryo transfer patient was put on progesterone support, tablet Aspirin $150 \mathrm{mg}$ OD and injection LMWH $40 \mathrm{mg}$ SC alternate day. ${ }^{19}$ days Post Embryo transfer her Beta hCG was $224 \mathrm{mIU} / \mathrm{ml}$. Repeat $\beta$ hCG 6 days later was $3189 \mathrm{mIU} / \mathrm{ml}$. Transvaginal ultrasound done which showed no evidence of intrauterine or adenexal gestational sac. Patient reported on 17/01/2020 (past 15 days of positive $\beta$ hCG) with spotting per vaginm. Ultrasound was suggestive of live cervical ectopic pregnancy. Patient was Haemodynamically stable and no active bleeding. $\beta$ hCG was $7487 \mathrm{mIU} / \mathrm{ml}$. Her baseline Haemogram, LFT, RFT, PT-INR done, which were normal. Fasting sugar was 130 $\mathrm{mg} / \mathrm{dl}$ and Post Prandial Blood sugar was $169 \mathrm{mg} / \mathrm{dl}$ with HbA1C of 6.9. Patient was put on Tablet Metformin 500 mg BD. MRI Pelvis was done to confirm Diagnosis of cervical ectopic On MRI There was well defined gestational sac $1.5 \times 2 \mathrm{~cm}$ in length and $10.4 \mathrm{~mm}$ in width (Figure 1) with fetal pole present (Figure 2). Gestational sac was located in upper part of cervical canal, abutting the internal OS (Figure 3). Internal OS was closed. Cervical length was $3.7 \mathrm{~cm}$ (Figure 4).

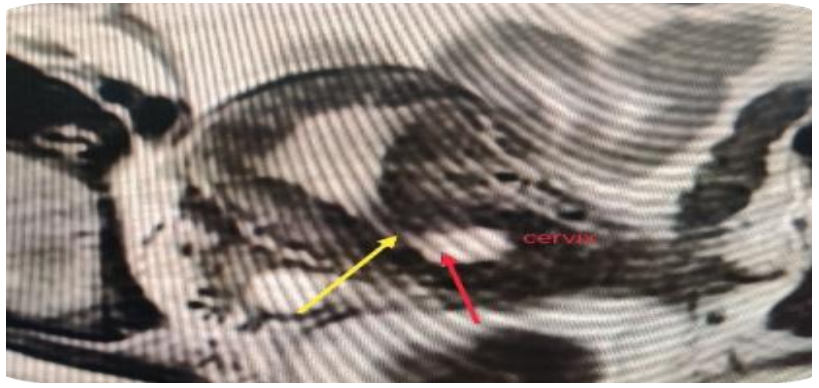

Figure 3: Yellow arrow showing internal OS. Red arrow showing gestational sac in endocervical canal abutting the internal.

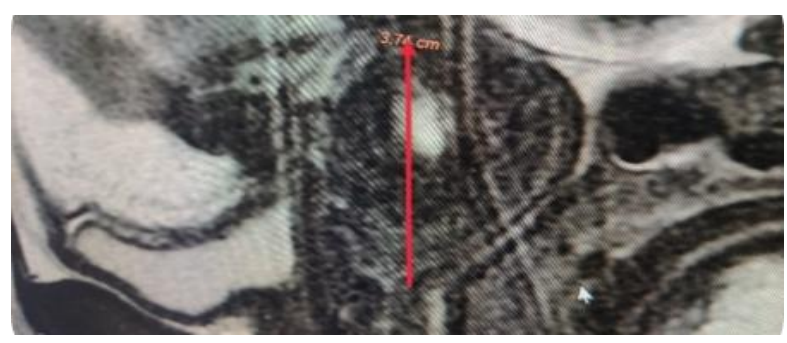

Figure 4: Cervical length $3.7 \mathrm{~cm}$. Gestational sac completely within cervical canal.

As the patient desired future fertility, conservative management with standard multidose protocol of methotrexate $1 \mathrm{mg} / \mathrm{kg}$ intramuscular was given on day $1,3,5$, and 7 with $0.1 \mathrm{mg} / \mathrm{kg}$ of Leucovorin IM on day $2,4,6$ and 8. Her CBC was repeated before each Methotrexate injection. Serum $\beta \mathrm{hCG}$ was done on day 1,3,5,7 and 11 which showed decreasing trend. Further serum $\beta$ hCG was followed weekly till complete resolution which was $12 \mathrm{mIU} / \mathrm{ml}$ on day 56 after methotrexate injection. Simultaneously patient was followed up with TVS which showed Mean sac diameter of $2 \mathrm{~cm}$ with fetal pole and cardiac activity on day 1 which was reduced to Mean sac diameter of $0.5 \mathrm{~cm}$ with no fetal pole on day 11 .

\section{DISCUSSION}

Cervical pregnancy first described by Rubin is defined as an implantation of a fertilized ovum in the cervical canal below the level of internal os. This results from implantation of blastocyst in the endocervical canal and is associated with higher morbidity and mortality. Differential diagnosis for cervical pregnancy includes incomplete abortion in which gestational sac is residing in cervix which can be differentiated by detecting 
'Sliding sign' on transvaginal ultrasound. ${ }^{5}$ In patients with incomplete abortion gentle pressure applied with transvaginal probe will demonstrate sliding between gestational sac and endocervical canal unlike an implanted cervical pregnancy. ${ }^{5}$ Furthermore, on colour Doppler ultrasonography high peri-trophoblastic velocity is seen in case of cervical pregnancy. ${ }^{5}$ Causes of cervical pregnancies are still unknown. One theory is that there is rapid transport of fertilized ovum to the cervical canal before it is capable of nidation at endometrium. ${ }^{6}$ All kinds of manipulations on cervix are considered as a risk factor for cervical pregnancies like dilatation and curettage, hysteroscopy, use of intrauterine device and pelvic inflammatory disease. ${ }^{7}$ After implantation, the cervical environment cannot satisfy the needs of the growing ovum, as normal placental attachment is hindered by the incomplete decidual reaction. As cervix consist of predominantly fibrous connective tissue and only $15 \%$ of smooth muscles resulting in insufficient decidual response in the cervix leads to abnormally adherent placenta, which explains the high intraoperative and postoperative maternal morbidity of this condition. ${ }^{7}$ At present ultrasonography has made diagnosis easier and accurate and availability of sensitive serum $\beta$-hCG assay which allows a more conservative therapeutic approach with consequent decrease in morbidity and mortality. Several treatment modalities are available and options for treatment depend on gestational period and the woman's desire for further fertility. Conservative management is the therapy of choice in a stable patient, but its success depends on gestational age. Different authors describe use of intraamniotic potassium chloride (KCL) or methotrexate (MTX) intraamniotic or systemic. ${ }^{8,9}$ Systemic methotrexate is the most common conservative treatment with either viable or non viable cervical pregnancy $<12$ weeks gestation and carries a success rate of $91 \% .^{10}$ But, primary methotrexate intramuscular injection is associated with a higher failure rate when fetal cardiac activity is present, initial serum hCG level $>10,000 \mathrm{mIU} / \mathrm{mL}$, gestational age of $>9$ weeks and a crown-rump length of $>10 \mathrm{~mm}$ is observed. ${ }^{11}$ Intraamniotic injection of potassium chloride may enhance the therapeutic effect of methotrexate Intramuscular route for methotrexate administration is usually preferred. The patient should be hemodynamically stable and must comply with post-treatment monitoring. Multidose methotrexate regimen $1.0 \mathrm{mg} / \mathrm{kg}$ body weight on days 1 , 3,5 and 7 interspaced by leucoverin $0.1 \mathrm{mg} / \mathrm{kg}$ body weight is preferred. Posttreatment decline in weekly serum beta hCG level reflects the successful therapeutic intervention. possible adverse effects of systemic methotrexate includes thrombocytopenia, leucopenia, elevated serum liver enzymes, fever and gastrointestinal symptoms. $^{12}$ Although intra-amniotic instillation of potassium chloride is more effective in the presence of fetal cardiac activity, the procedure requires a high level of skill and familiarity and is associated with the risk of hemorrhage. $^{13}$ Therefore, in our case, we chose to manage the patient with systemic methotrexate. In our facility, we had an experience on conservative management of 6 weeks old triplet heterotropic cesaerian scar ectopic pregnancy with systemic methotrexate. 14 Surgical conservative technique include angio embolization of feeding uterine arteries and hysteroscopic resection. ${ }^{15,16}$ vaginal ligation of cervical arteries, bilateral uterine or hypogastric artery ligations. ${ }^{17}$

\section{CONCLUSION}

Cervical ectopic pregnancy is rare form of ectopic pregnancy. There are no definitive guidelines for treatment. Intramuscular methotrexate treatment for stable patients is safe, effective and fertility conserving treatment.

\section{Funding: No funding sources \\ Conflict of interest: None declared \\ Ethical approval: Not required}

\section{REFERENCES}

1. Anev I, Wang J, Palep-Singh M, Seif MW. Monochorionic diamniotic twin cervical ectopic pregnancy following assisted conception: a case report. The Journal of Reproductive Medicine. 2013;58(9-10):445-7.

2. Baron KT, Babagbemi KT, Arleo EK, Asrani AV, Troiano RN. Emergent complications of assisted reproduction: expecting the unexpected. Radiographics. 2013;33(1):229-44.

3. Lin EP, Bhatt S, Dogra VS. Diagnostic clues to ectopic pregnancy. Radiographics. 2008;28(6):166171.

4. Mehta TS, Levine D, Beckwith B. Treatment. Obstet Biol Reprod (Paris). 2003;32(7).

5. Jurkovic D, Hacket E, Campbell S. Diagnosis and treatment of early cervical pregnancy: A review and a report of two cases treated conservatively. Ultrasound Obstet Gynecol. 1996;8:373-80.

6. Studdiford WE. Cervical pregnancy: A partial review of the literature and a report of two probable cases. Am J Obstet Gynecol. 1945;49:169-85.

7. Cerveira I, Costa C, Santos F, Santos L, Cabral F. Cervical ectopic pregnancy successfully treated with local methotrexate injection. Fertil Steril. 2008;90(5):2005.e7-2005.

8. Matteo M, Nappi L, Rosenberg P, Greco P. Combined medical-hysteroscopic conservative treatment of a viable pregnancy: A case report. J Minim Invasive Gynecol. 2006;13:345-7.

9. Lin H, Kung FT. Combination of laparoscopic bilateral uterine artery ligation and intraamniotic methotrexate injection for conservative management of cervical pregnancy. J Am Assoc Gynecol Laparosc. 2003;10:215-8.

10. Kung FT, Chang SY. Efficacy of methotrexate treatment in viable and nonviable cervical pregnancies. Am J Obstet Gynecol. 1999;181:143844. 
11. Hung TH, Shau WY, Hsieh TT, Hsu JJ, Soong YK, Jeng CJ. Prognostic factors for an unsatisfactory primary methotrexate treatment of cervicalpregnancy: a quantitative review. Hum Reprod. 1998.

12. . Fernandez H, Bourget P, Lelaidier C, Doumerc S, Frydman R. Methotrexate treatment of unilateral twin ectopic pregnancy: case report and pharmacokinetic considerations. Ultrasound Obstet Gynecol. 1993;3:357-9.

13. Leeman LM, Wendland CL. Cervical ectopic pregnancy. Diagnosis with endovaginal ultrasoundexamination and successful treatment with methotrexate. Arch Fam Med. 2000;9:72-7.

14. Nilofar Y, Dharam S, Meena S, Vijaya B. Successful management of a triplet heterotropic caesarean scar pregnancy in spontaneous conception. International
Journal of Reproduction, Contraception, Obstetrics and Gynecology. 2019;8:3808.

15. Nelson RM. Bilateral internal iliac artery ligation in cervical pregnancy: conservation of reproductive function. Am J Obstet Gynecol. 1979;134:145-50.

16. Hardy TJ. Hysteroscopic resection of a cervical ectopic pregnancy. J Am Assoc Gynecol Laparosc. 2002;9:370-1.

17. Yazici G, Aban M, Arslan M, Pata O, Oz U. Treatment of cervical viable pregnancy with a single intraamniotic methotrexate injection: a case report. Arch Gynecol Obstet. 2004;270:61-3.

Cite this article as: Yelurkar NI, Satia MN,

Badhwar VR. Medical management of cervical pregnancy following in vitro fertilization. Int $\mathbf{J}$ Reprod Contracept Obstet Gynecol 2021;10:2507-10. 